\title{
Differences in liquid cloud droplet effective radius and number concentration estimates between MODIS collections 5.1 and 6 over global oceans
}

\author{
John Rausch ${ }^{1}$, Kerry Meyer ${ }^{2}$, Ralf Bennartz ${ }^{1,3}$, and Steven Platnick ${ }^{2}$ \\ ${ }^{1}$ Department of Earth and Environmental Sciences, Vanderbilt University, Nashville, TN 37235, USA \\ ${ }^{2}$ NASA Goddard Space Flight Center, Greenbelt, Maryland, 20771, USA \\ ${ }^{3}$ Space Science and Engineering Center, University of Wisconsin, Madison, Madison, WI 53706, USA \\ Correspondence to: John Rausch (john.rausch@vanderbilt.edu)
}

Received: 3 August 2016 - Discussion started: 29 September 2016

Revised: 27 March 2017 - Accepted: 30 March 2017 - Published: 8 June 2017

\begin{abstract}
Differences in cloud droplet effective radius and cloud droplet number concentration (CDNC) estimates inferred from the Aqua-MODIS (Moderate Resolution Imaging Spectroradiometer) collections 5.1 (C5.1) and 6 (C6) cloud products (MYD06) are examined for warm clouds over global oceans for the year 2008. Individual pixel level retrievals for both collections are aggregated to $1^{\circ} \times 1^{\circ}$ and compared globally and regionally for the three main spectral channel pairs used for MODIS cloud optical property retrievals. Comparisons between both collections are performed for cases in which all three effective radii retrievals are classified by the MODIS cloud product as valid. The contribution to the observed differences of several key MYD06 Collection 6 algorithm updates are also explored, with a focus on changes to the surface reflectance model, assumed solar irradiance, above-cloud emission, cloud-top pressure (CTP), and pixel registration. Global results show a neutral to positive $\left(>50 \mathrm{~cm}^{-3}\right)$ change for C6-derived CDNC relative to $\mathrm{C} 5.1$ for the 1.6 and $2.1 \mu \mathrm{m}$ channel retrievals, corresponding to a neutral to $-2 \mu \mathrm{m}$ difference in droplet effective radius $\left(r_{\mathrm{e}}\right)$. For $3.7 \mu \mathrm{m}$ retrievals, CDNC results show a negative change in the tropics, with differences transitioning toward positive values with increasing latitude spanning -25 to $+50 \mathrm{~cm}^{-3}$ related to a +2.5 to $-1 \mu \mathrm{m}$ transition in effective radius. Cloud optical thickness $(\tau)$ differences were small relative to effective radius and found to not significantly impact CDNC estimates. Regionally, the magnitude and behavior of the annual CDNC cycle are compared for each effective radius retrieval. Results from this study in-
\end{abstract}

dicate significant inter-collection differences in aggregated values of effective radius due to changes to the precomputed retrieval lookup tables (LUTs) for ocean scenes, changes to retrieved cloud-top pressure, solar irradiance, or above-cloud thermal emission, depending upon spectral channel. The observed differences between collections may have implications for existing MODIS-derived climatologies and validation studies of effective radius and CDNC.

\section{Introduction}

Marine stratocumuli play a large role in the modulation of the Earth's radiative balance and hydrological cycle, owing to their persistence and large areal extent. They are maintained by moisture flux from the sea surface, longwave cooling, and dry air entrainment at the cloud top. Confined to the planetary boundary layer, most often in subtropical subsidence areas, they are susceptible to the influences of anthropogenic aerosols. Aerosol perturbation manifests changes though several mechanisms. Through the first indirect aerosol effect, anthropogenic influences potentially alter the degree of reflection of shortwave radiation by distributing a given quantity of cloud water over a larger number of droplets compared to an unperturbed cloud by supplying additional cloud condensation nuclei (CCN; Twomey, 1974). This increase in cloud albedo provides a local cooling effect as the cloud-top temperature (CTT) is near the sea surface temperature, producing a negligible longwave radiative ef- 
fect. With a decrease in droplet effective radius $\left(r_{\mathrm{e}}\right)$ from the addition of $\mathrm{CCN}$, autoconversion efficiency can decrease, reducing precipitation efficiency (Albrecht, 1989) and potentially increasing the overall lifetime of clouds, augmenting the first indirect effect (Lohmann and Feichter, 2005). This naturally leads to a need for estimates of cloud droplet number concentration (CDNC) from observations to better understand the natural background and anthropogenic contributions to cloud droplet number concentration.

Satellites offer an opportunity to address this need through their global observational area spanning decades. The National Aeronautics and Space Administration's (NASA) Moderate Resolution Imaging Spectroradiometer (MODIS) is an instrument suited for this task. Flown aboard two Earthobserving satellites (Terra and Aqua), MODIS provides observations in the appropriate spectral bands to infer cloud optical thickness $(\tau)$ and droplet effective radius through the bi-spectral method of Nakajima and King (1990). From the retrieved cloud optical thickness and droplet effective radius, cloud droplet number concentration can be estimated (Brenguier et al., 2000). NASA provides retrievals of the cloud optical properties through the MODIS cloud product (MOD06 and MYD06 for Terra and Aqua, respectively); note the MOD06 and MYD06 products are produced by the same algorithm (Platnick et al., 2015, 2017). As passive imager cloud remote sensing science evolves, the MODIS cloud product undergoes periodic updates to the cloud screening and retrieval algorithms, which are collectively implemented and reprocessed as "collections". Collection 6 (C6) is the most recent release of the cloud product and includes several changes that propagate through to estimates of cloud microphysical properties relative to its predecessor, Collection 5.1 (C5.1; Platnick et al., 2015). Since there is an existing body of research based upon Collection 5.1 of effective radius (e.g., Zhang and Platnick, 2011; Painemal and Zuidema, 2011) and CDNC (e.g., Zeng et al., 2014; Ahmad et al., 2013), there is a need to understand how these retrievals differ between collections. In this study, we investigate and highlight the differences in retrieved cloud microphysical properties manifested both in effective radius and CDNC between both collections using 1 year of AquaMODIS observations of warm clouds over global oceans in an attempt to understand the differences in CDNC from the respective products.

\section{Data and methods}

The MODIS Collection 5.1 cloud product provides estimates of cloud optical thickness $(\tau)$ and droplet effective radius $\left(r_{\mathrm{e}}\right)$ in addition to cloud screening, quality control flags, and ancillary data relevant to the computation of cloud droplet number concentration. For most parameters derived from visible, near, and shortwave infrared (IR) channels, the spatial resolution is $1 \times 1 \mathrm{~km}$ at nadir. Some parameters, such as those derived from thermal infrared channels, are provided at a $5 \times 5 \mathrm{~km}$ resolution. The $\mathrm{C} 5.1$ cloud product applies a Clear Sky Restoral (CSR) algorithm that identifies pixels that are expected to be only partially cloudy, and excludes them from the cloud optical properties retrieval, essentially limiting C5.1 data to cloudy scenes only. In addition, the C5.1 $r_{\mathrm{e}}$ retrievals using the 1.6 and $3.7 \mu \mathrm{m}$ channels are given as a difference relative to the $2.1 \mu \mathrm{m} r_{\mathrm{e}}$ value and are therefore dependent upon the success of the $2.1 \mu \mathrm{m}$ retrieval.

The Collection 6 cloud product offers improvements in retrievals of several relevant parameters for CDNC estimation. Changes to the optical and microphysical retrievals for C6 include improvements to the forward radiative transfer model used to create the precalculated cloud retrieval lookup tables (LUTs), re-registration of the visible and near-IR focal planes for MODIS-Aqua, and explicit reporting of all three spectral channel pair effective radius retrievals (Platnick et al., 2015); cloud-top property retrieval changes for C6 include additional cloud-top temperature and pressure retrievals at $1 \times 1 \mathrm{~km}$ spatial resolution and improvements to the characterization of low-level clouds over water surfaces, among others (Platnick et al., 2015). With respect to the assessment of pixel quality, the CSR algorithm is still applied and its results are reported in the cloud product, but unlike C5.1 cloud optical property retrievals are attempted on pixels identified as partly cloudy and, if successful, are written to the cloud product separate from the heritage cloudy retrievals (Platnick et al., 2015). Note that pixels identified by the CSR algorithm as being not cloudy (e.g., false cloudy sunglint or thick aerosols such as smoke or dust) remain excluded from the cloud optical property retrievals. A year of MODIS-Aqua C5.1 and C6 data, corresponding to calendar year 2008, is used in this investigation.

\subsection{Calculating CDNC}

Relating cloud droplet number concentration to retrievals of optical thickness and droplet effective radius requires an estimate of cloud liquid water content. To attain CDNC, which is not a parameter in the MODIS cloud product, the vertical structure is assumed to follow the so-called adiabatically stratified cloud model (Brenguier et al., 2000). This model accounts for a linear increase in cloud liquid water content as a saturated air parcel rises through a cloud's vertical extent while undergoing droplet growth as the parcel cools moistadiabatically. As marine boundary layer clouds are typically shallow, the temperature is nearly constant, so it follows that the amount of condensate formed through adiabatic ascent can be assumed to be constant. The following relationships, adapted from Bennartz (2007), are presented as a summary of how CDNC relates to the adiabatic cloud model. The adiabatic liquid water content $w_{\mathrm{AD}}$ at any point $h$ above the cloud base can be expressed as

$w_{\mathrm{AD}}(h, T)=c_{w}(T) h$, 


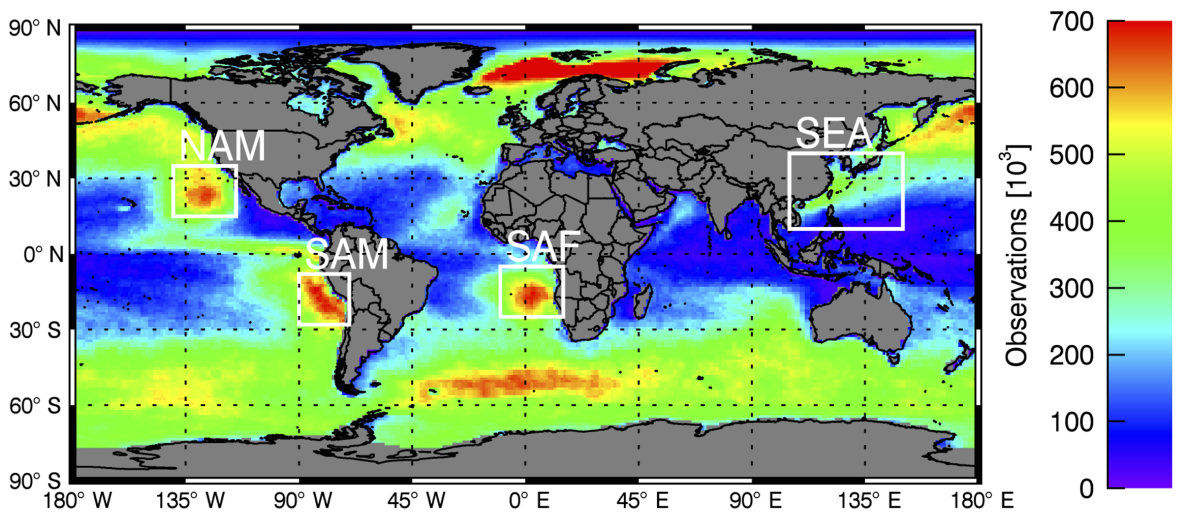

Figure 1. Annual total of Aqua-MODIS liquid phase cloud observations where all three effective radii retrievals are valid per $1 \times 1^{\circ}$ grid box. Focus regions are overlain.

where $c_{w}$ is the mass of condensate formed per unit volume for each meter of ascent and $T$ is the cloud-top temperature. The $c_{w}$ parameter is derived from the Clausius-Clapeyron relationship and is primarily a function of temperature and, to a lesser degree, pressure. For this study, an assumed cloudtop pressure (CTP) of $850 \mathrm{hPa}$ is used, which corresponds to a geopotential height of approximately $1500 \mathrm{~m}$. For marine stratocumulus regions such as the southeast Pacific, this height is near the mean top of the boundary layer (von Engeln and Teixeira, 2013) around Aqua's 13:30 local equatorial crossing time (Ho et al., 2015).

Relating the liquid water content profile to the cloud optical properties, Brenguier et al. (2000) express the adiabatic liquid water path as

$$
W_{\mathrm{AD}}=\frac{5}{9} \rho_{1} \tau r_{\mathrm{e}, \mathrm{top}}
$$

where the effective radius is the value at cloud top. Accounting for cloud-top entrainment of dry air, observed and modeled liquid water paths are typically near $80 \%$ of the purely adiabatic value (Duynkerke et al., 2004; Pawlowska and Brenguier, 2003). The $c_{w}$ parameter in this study is therefore scaled to approximately $80 \%$ of the purely adiabatic value, in order to avoid overestimation of the condensate observed by MODIS.

With the cloud optical parameters, Bennartz (2007) expresses CDNC as

$N=\frac{\tau^{3}}{k}\left[2 W_{\mathrm{AD}}\right]^{-5 / 2}\left[\frac{3}{5} \pi Q\right]^{-3}\left[\frac{3}{4 \pi \rho_{1}}\right]^{-2} c_{w}^{1 / 2}$,

where $k$ encapsulates the skewness and dispersion of the cloud droplet size distribution, $Q$ is the scattering efficiency, and $\rho_{1}$ is the density of liquid water. Analytically, $k=\frac{r_{v}^{3}}{r_{\mathrm{e}}^{3}}$, where $r_{\mathrm{v}}$ is the volume mean droplet radius. For marine boundary layer clouds $k=0.8$ is assumed to be a representative value for this study (Brenguier et al., 2011; Martin et al.,
1994), although Painemal and Zuidema (2011) suggest that $k=0.88$ may be more representative for droplets near the cloud top, resulting in a narrower cloud droplet size distribution. As the size parameters for cloud droplets approach the geometric optics limit, the asymptotic value of 2 is assumed for $Q$.

\section{Results}

\subsection{Global-scale common pixel comparison}

Common pixel scenes are those in which all three effective radius retrievals are valid for both collections with otherwise consistent selection criteria. A common pixel selection allows for an objective comparison of effective radius and CDNC estimates between both collections, free of the influence of pixel population differences due to, for example, reclassification of cloud phase due to changes to the cloud thermodynamic phase algorithm (Marchant et al., 2016), or where one or more effective radius retrievals have failed between collections (Cho et al., 2015). The global distribution of the total MODIS-Aqua common pixel count for calendar year 2008 is shown in Fig. 1.

Figure 2 shows mean annual C6 values and C6-C5.1 differences in MYD06 cloud droplet effective radius for common pixel scenes, aggregated globally to a $1^{\circ} \times 1^{\circ}$ equal angle grid for calendar year 2008, from the 1.6, 2.1, and $3.7 \mu \mathrm{m}$ channels. For $r_{\mathrm{e}, 1.6}$, C6 retrievals are smaller than C5.1 over most of the global oceans (differences generally less than $1 \mu \mathrm{m}$ ), with the largest differences (greater than $2 \mu \mathrm{m}$ ) occurring near the Baja California peninsula. In equatorial regions of the Indian and west Pacific basins, as well as over sea ice regions in the northern high latitudes above $60^{\circ} \mathrm{N}$, however, $r_{\mathrm{e}, 1.6}$ differences are largely neutral to slightly positive. C6 retrievals of $r_{\mathrm{e}, 2.1}$ are predominantly smaller than C5.1 (differences less than $1 \mu \mathrm{m}$ ), with the greatest disagreement between collections occurring in the tropics. For $r_{\mathrm{e}, 3.7}$, 
(a)

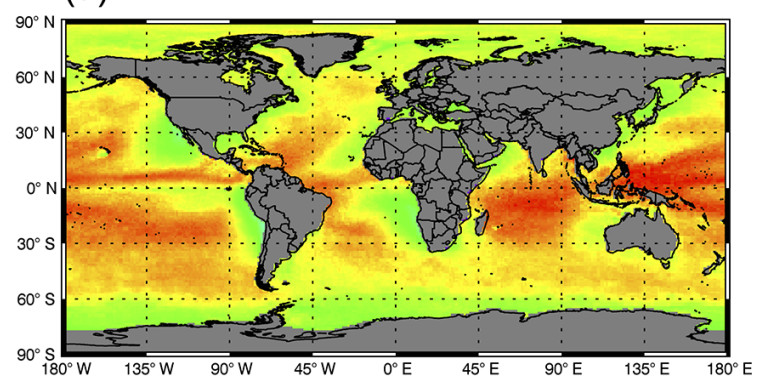

(b)

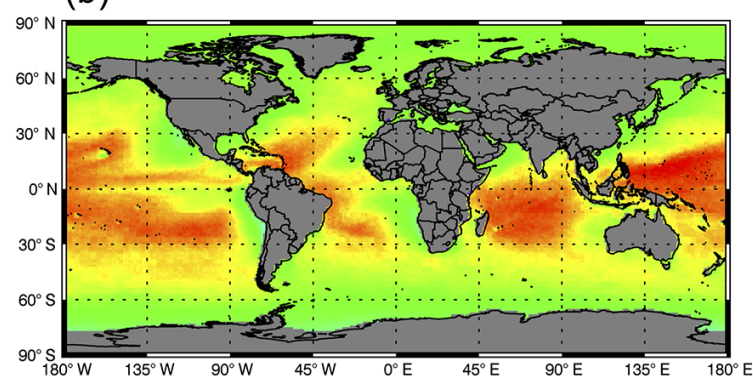

(c)

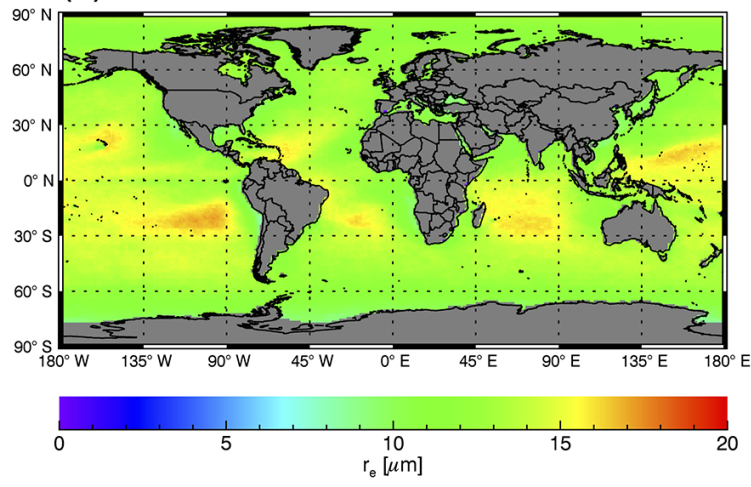

(d)

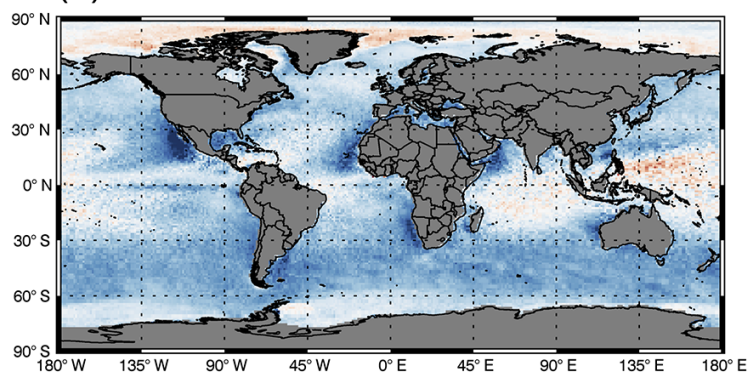

(e)

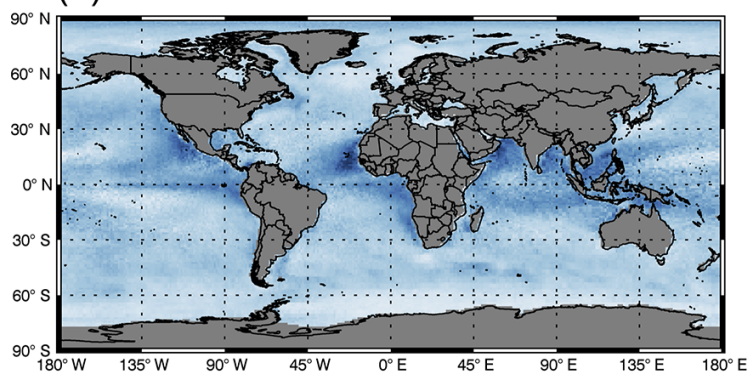

(f)

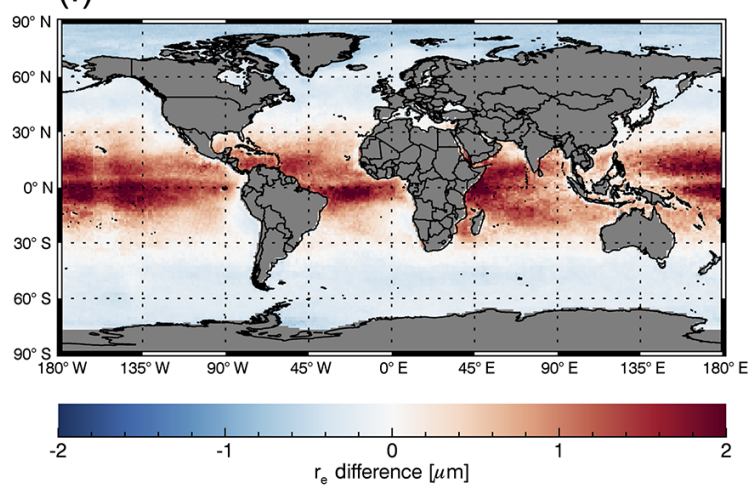

Figure 2. Mean annual Collection 6 cloud droplet effective radius for calendar year 2008 for the (a) $1.6 \mu \mathrm{m}$, (b) $2.1 \mu \mathrm{m}$, and (c) $3.7 \mu \mathrm{m}$ channels and C6-C5.1 effective radius differences for the (d) $1.6 \mu \mathrm{m}$, (e) $2.1 \mu \mathrm{m}$, and (f) $3.7 \mu \mathrm{m}$ channels.

there is a latitudinal gradient in the retrieval differences, with positive inter-collection differences in the tropics $(\mathrm{C} 6>\mathrm{C} 5.1$ by more than $2 \mu \mathrm{m}$ ) transitioning to slightly negative values $(\mathrm{C} 6<\mathrm{C} 5.1$ by less than $2 \mu \mathrm{m})$ at higher latitudes.

The relationship between the inter-collection shifts in $r_{\mathrm{e}}$ do not necessarily imply that the cloud liquid water path profile is steepened in C6 by the decrease in $r_{\mathrm{e}, 1.6}$ and $r_{\mathrm{e}, 2.1}$ and the increase of $r_{\mathrm{e}, 3.7}$ at low latitudes. Contributing effective radii in this study are not required to conform to an adiabatically stratified profile and are likely subject to retrieval artifacts, complicating the determination of the liquid water content profile. This is especially the case at lower latitudes where convective clouds are more dominant and inhomogeneous relative to stratiform clouds.
Patterns similar to those of effective radius are mirrored in the respective CDNC C6 average and inter-collection difference plots of Fig. 3. As shown in Fig. 3d-e, for the $N_{1.6}$ and $N_{2.1}$ estimates, the differences are generally neutral to positive, i.e., C6 $>\mathrm{C} 5.1$, with values over $+50 \mathrm{~cm}^{-3}$ occurring along coastal boundaries in the subtropical subsidence zones. Figure $3 \mathrm{f}$ shows that $N_{3.7}$ from C6 is smaller than C5.1 in the tropics and generally larger at latitudes higher that $45^{\circ}$. Note that of the three spectral channels used for $r_{\mathrm{e}}$ retrievals, the sensitivity of the $3.7 \mu \mathrm{m}$ channel is weighted closest to cloud top (Platnick, 2000), and $r_{\mathrm{e}, 3.7}$ is therefore considered to be the most appropriate effective radius for estimating CDNC based upon the assumption of the adiabatic model that the effective radius is the cloud-top value. 
(a)

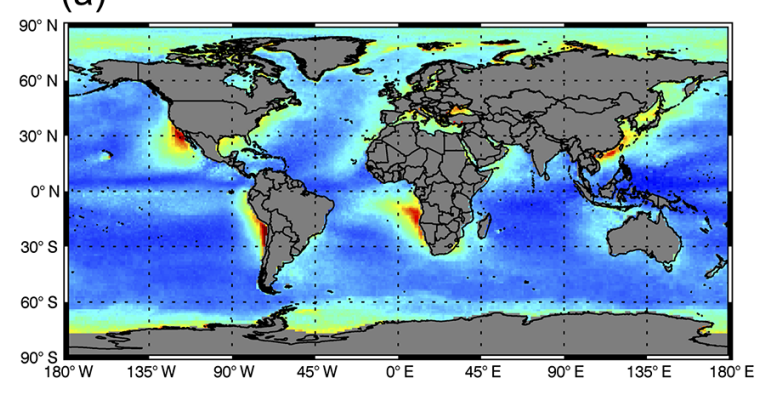

(b)

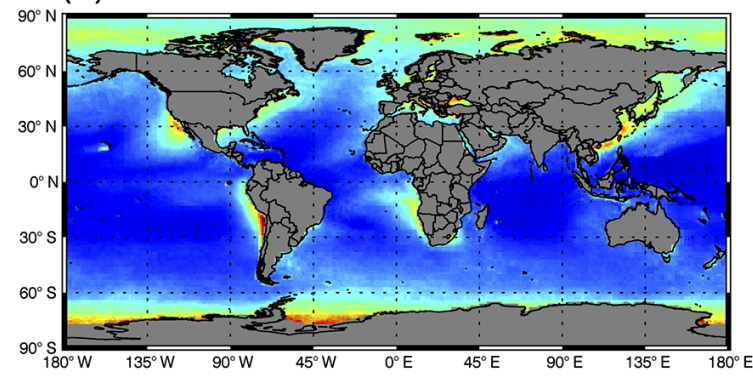

(c)

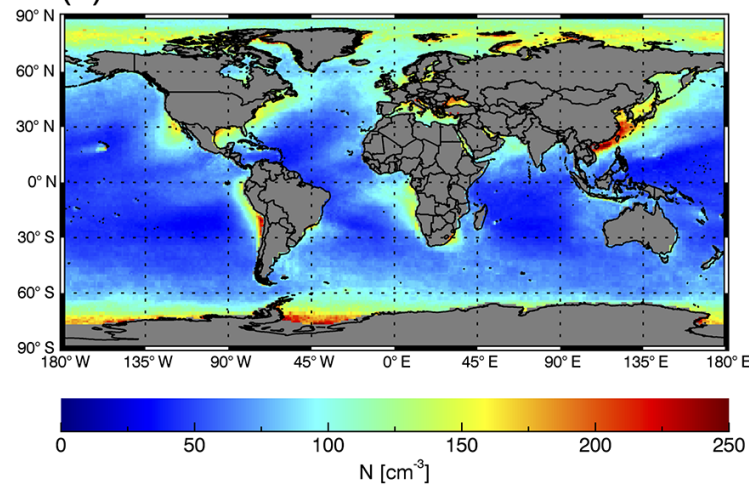

(d)

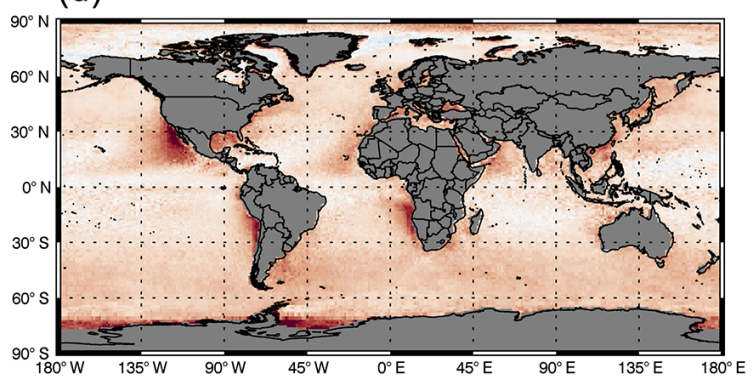

(e)

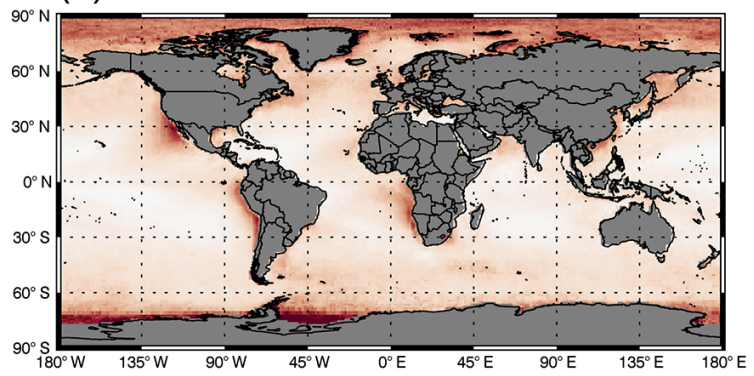

(f)

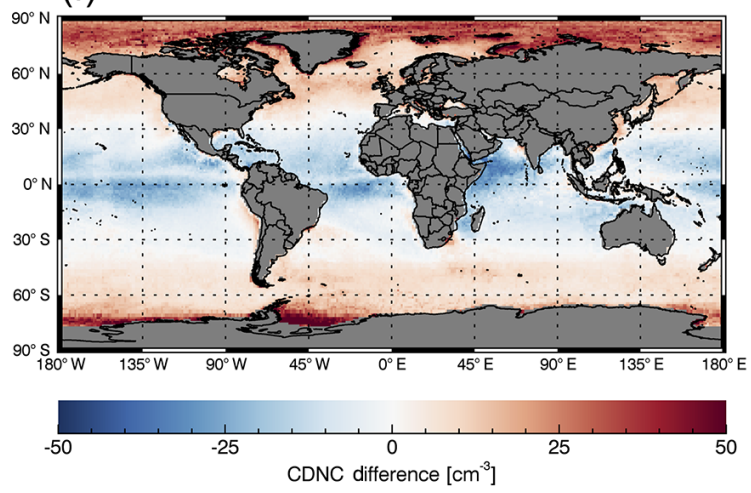

Figure 3. Mean annual Collection 6 cloud droplet number concentration for year 2008 for the (a) $1.6 \mu \mathrm{m}$, (b) $2.1 \mu \mathrm{m}$, and (c) $3.7 \mu \mathrm{m}$ channels and C6-C5.1 CDNC differences for the (d) $1.6 \mu \mathrm{m}$, (e) $2.1 \mu \mathrm{m}$, and (f) $3.7 \mu \mathrm{m}$ channels.

Cloud optical thickness, which is another necessary retrieved parameter for estimation of CDNC, is neutral to slightly higher in aggregated retrievals for Collection 6 (not shown). For regions in which stratocumuli are often present, generally in the subtropical subsidence zones, C6 cloud optical thickness is within 0.25 of C5.1. This translates to a relative overestimation by $\mathrm{C} 6$ of roughly $2 \%$. Considering the relatively weak sensitivity of CDNC to changes in cloud optical thickness relative to droplet effective radius, this results in an increase of C6 CDNC by less than $1 \%$.

\subsection{Algorithmic and calibration factors in inter-collection differences}

Due to the strong sensitivity to effective radius $\left(N \propto r_{\mathrm{e}}^{-5 / 2}\right)$ in Eq. (3), larger effective radii translate into lower relative CDNC (and vice versa), thus the $r_{\mathrm{e}}$ differences shown in Fig. 2 largely explain the CDNC differences observed in Fig. 3. As previously noted, the use of common pixels in the analysis in Sect. 3.1 removes the influence of pixel population differences between the two collections. The large effective radius differences between C5.1 and C6 observed in Fig. 2 are therefore the result of either changes to the MYD06 optical property retrieval algorithm itself or changes to upstream or ancillary products such as the Level $1 \mathrm{~b}$ calibrated 
(a)

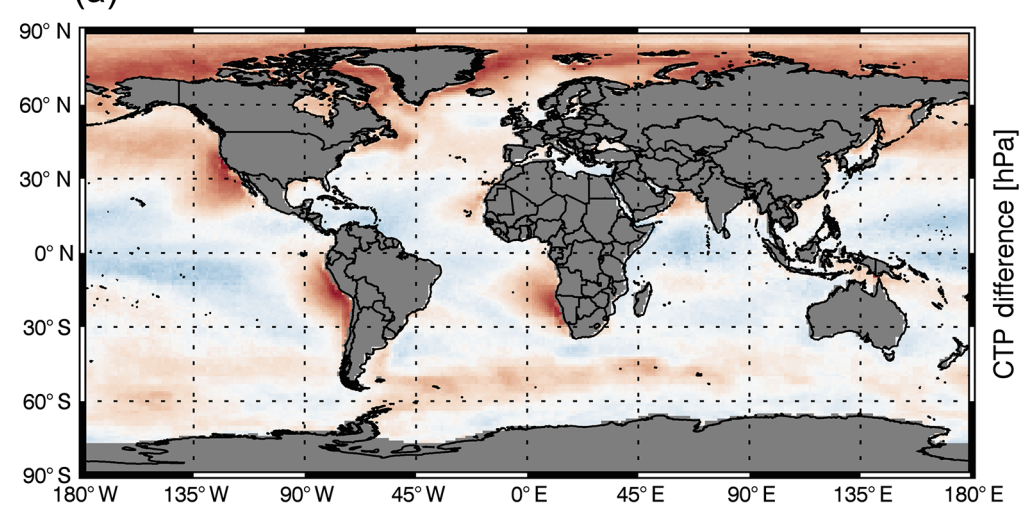

(b)

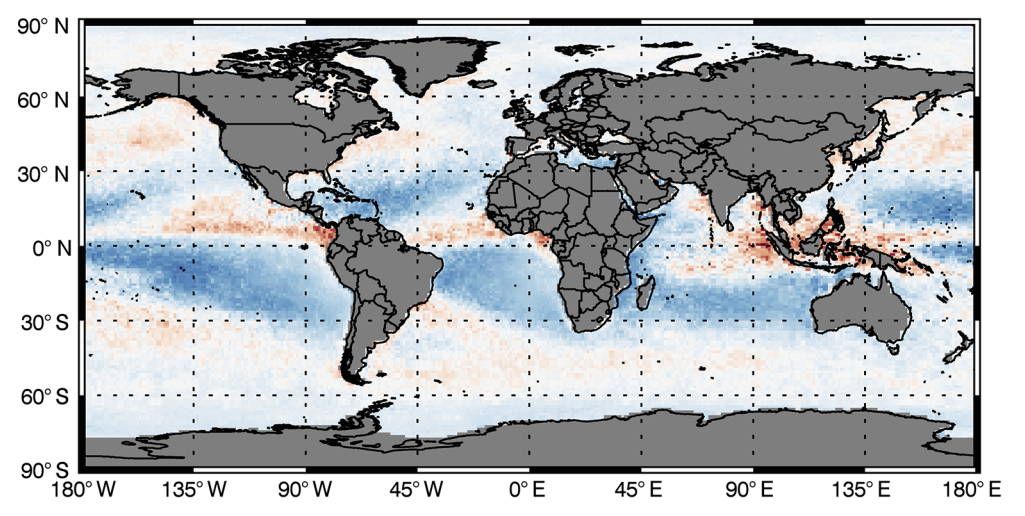

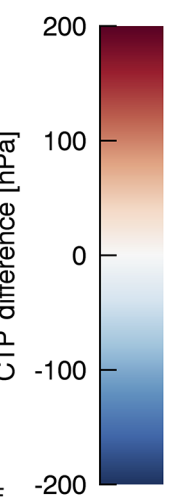

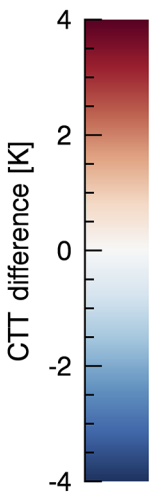

Figure 4. Cloud-top pressure (a) and temperature (b) differences between aggregated $1 \mathrm{~km}$ resolution C6 and $5 \mathrm{~km}$ resolution C5.1 for the common pixel population.

radiometric data or the MYD06 cloud-top property retrieval algorithm.

For C6, changes to the liquid phase cloud optical property retrieval algorithm were, for the case of $r_{\mathrm{e}, 1.6}$ and $r_{\mathrm{e}, 2.1}$, limited primarily to the precomputed retrieval lookup tables. The change having the most significant impact on the $r_{\mathrm{e}}$ retrievals is the use of new LUTs for retrievals over ocean, which incorporate an ocean surface bidirectional reflectance model directly into the LUT that uses the Cox-Munk wind speed and direction-dependent wave-slope distribution (Cox and Munk, 1954b, a). Previously in C5.1 the same LUT was used over land and ocean scenes, with the ocean surface assumed to be a Lambertian reflector with $5 \%$ albedo (Platnick et al., 2017). Changes to input datasets, such as Aqua Level $1 \mathrm{~b}$ re-registration of the visible and near-IR focal plane and updates to the cloud-top property retrievals, are also found to significantly impact the $r_{\mathrm{e}}$ retrievals. Figures 5, 6, and 7 show a single granule case study illustrating the impacts of these changes. An Aqua-MODIS granule of open and closed cell marine stratocumuli acquired off the coast of Baja California on 9 June 2014 (21:55 UTC) was selected. The true color images, $1 \mathrm{~km} \mathrm{CTP,} \tau$, and $r_{\mathrm{e}, 2.1}$, are shown in Fig. 5ad. A region of sunglint is visible slightly west of nadir below $15^{\circ} \mathrm{N}$. Also, a glory is present east of nadir above $23^{\circ} \mathrm{N}$, which is evident in the difference plots in Fig. 6. The C5.1 to C6 $r_{\mathrm{e}, 1.6}, r_{\mathrm{e}, 2.1}$, and $r_{\mathrm{e}, 3.7}$ changes, defined here as the difference $r_{\mathrm{e}, \lambda}(\mathrm{C} 6)-r_{\mathrm{e}, \lambda}(\mathrm{C} 5.1)$, are shown in Fig. 6a-c. Note that purple colors arise in regions where adjacent pixels have positive (red) and negative (blue) differences in effective radii. Subsequent rows in Fig. 6 show the individual impacts of the C6 changes listed above.

The impacts of the new LUT for ocean scenes on $r_{\mathrm{e}, 1.6}$, $r_{\mathrm{e}, 2.1}$, and $r_{\mathrm{e}, 3.7}$ are shown in Fig. 6d-f. This change primarily impacts $r_{\mathrm{e}}$ retrievals for optically thinner clouds ( $\tau$ roughly $<2$ to 3 ) and those over sunglint, lowering $r_{\mathrm{e}}$ by up to $1 \mu \mathrm{m}$. The strength of this effect is dependent on the orthogonality of the solution space, and thus the impacts are largest for $r_{\mathrm{e}, 1.6}$ and smallest for $r_{\mathrm{e}, 3.7}$. These $r_{\mathrm{e}}$ decreases due to LUT changes can be offset or enhanced, depending on the location of the pixel relative to cloud illumination or shadowing, by the effects of the Aqua Level $1 \mathrm{~b}$ re-registration of the visible and near-IR focal plane, shown in Fig. $6 \mathrm{~g}-\mathrm{i}$ that are again strongest on $r_{\mathrm{e}, 1.6}$ due to enhanced LUT non-orthogonality $\left(r_{\mathrm{e}, 3.7}\right.$ is largely unaffected). The largest contribution to the $r_{\mathrm{e}, 2.1}$ changes observed in Fig. 2 result from the updates to the cloud-top pressure retrievals, which are discussed in de- 
(a)

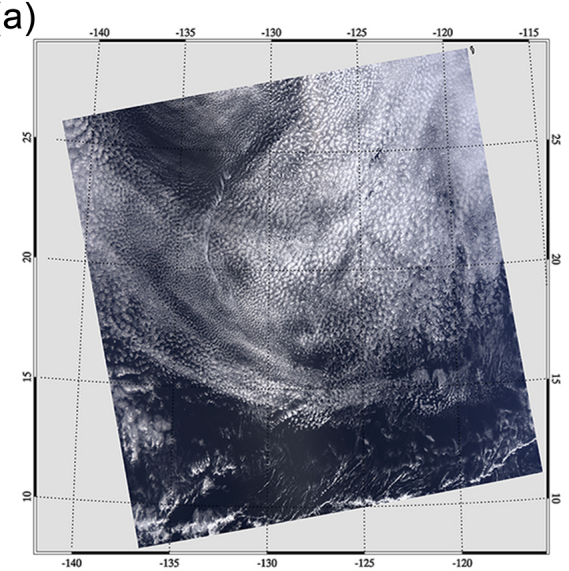

(c)

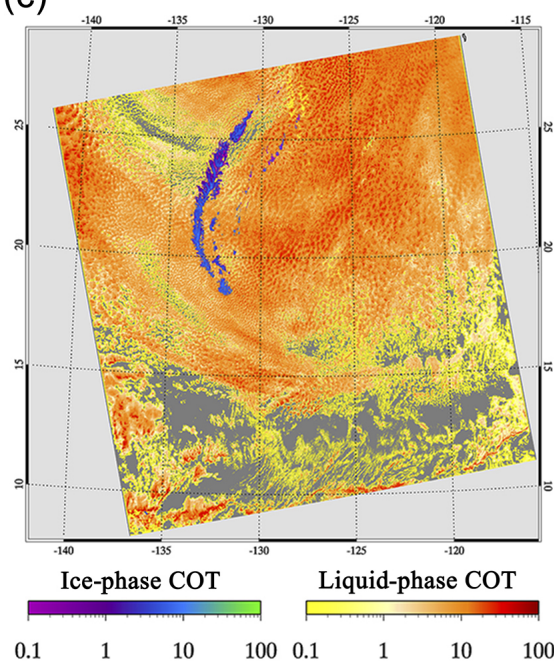

(b)

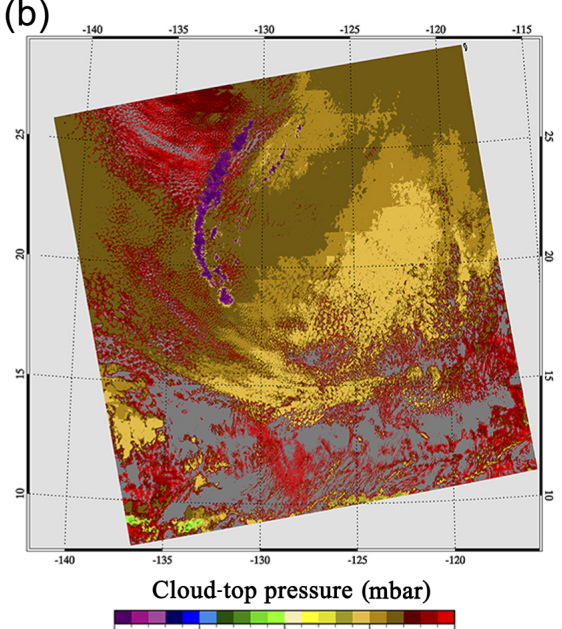

(d)

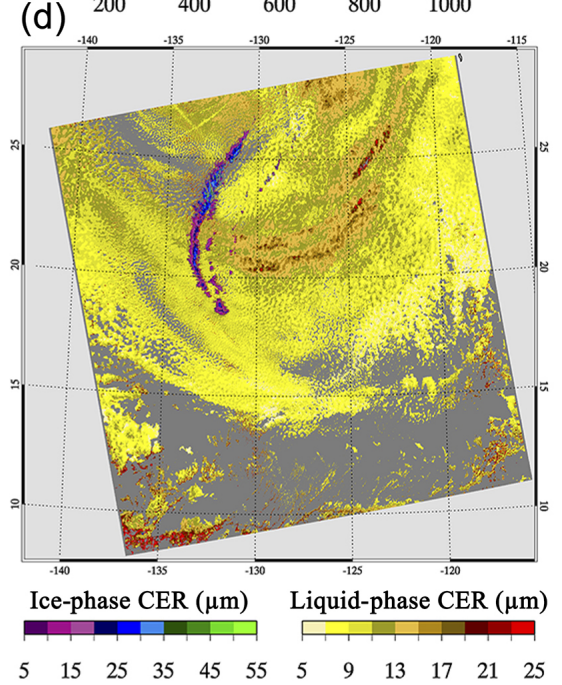

Figure 5. (a) True color image, C6 (b) $1 \mathrm{~km} \mathrm{CTP,} \mathrm{(c)} \mathrm{cloud} \mathrm{optical} \mathrm{thickness,} \mathrm{and} \mathrm{(d)} 2.1 \mu \mathrm{m}$ effective radius for a MODIS-Aqua granule acquired off the coast of Baja California on 9 June 2014 (21:55 UTC).

tail in Baum et al. (2012). The impacts on each channel are shown in Fig. 6j-1. For the liquid phase clouds in this granule, C6 CTP is largely higher than in C5.1 with increases of $100 \mathrm{hPa}$ or more (not shown). Higher CTP, i.e., lower cloudtop height, results in larger above-cloud atmospheric gaseous absorption corrections, brighter top of cloud reflectance, and thus smaller $r_{\mathrm{e}}$ from all three spectral channels, by up to $1 \mu \mathrm{m}$ or more. The global yearly mean CTP change for 2008 is shown in Fig. 4a, again illustrating that C6 CTP is largely higher than in C5.1, particularly over the marine stratocumulus regions where CTP has been increased to better place the height of the capping inversions (Baum et al., 2012). In contrast, in regions where the liquid cloud occurrence is low (e.g., the tropics; see Fig. 1) C6 CTP slightly decreases.

While the above C6 changes largely explain the intercollection differences for $r_{e 1.6}$ and $r_{e 2.1}$, algorithm updates for the $r_{e 3.7}$ retrieval were more extensive, involving fixes to known shortcomings in the C5.1 algorithm, and their net contribution to the dissimilar difference patterns shown in Fig. 2 are unclear. Retrieved $r_{e 3.7}$ decreases resulting from the CTP changes are enhanced by a correction to the assumed band-averaged solar irradiance $\left(F_{0}\right)$ at $3.7 \mu \mathrm{m}$. For $\mathrm{C} 6, \mathrm{~F}_{0}$ is smaller than for $\mathrm{C} 5.1$ and earlier versions $\left(10.9 \mathrm{~W} \mathrm{~m}^{-2} \mu \mathrm{m}^{-1}\right.$ for $\mathrm{C} 6$ versus $11.7 \mathrm{~W} \mathrm{~m}^{-2} \mu \mathrm{m}^{-1}$ for C5.1), resulting in a decrease of $r_{\mathrm{e}, 3.7}$ by $1 \mu \mathrm{m}$ or more, as shown in Fig. 7a. However, above-cloud atmospheric emission, previously ignored in C5.1, is now accounted for in C6 and yields a sizably larger $r_{\mathrm{e}, 3.7}$, on the order of $1 \mu \mathrm{m}$ or more, as shown in Fig. $7 \mathrm{~b}$. The cumulative effects of the $\mathrm{C} 6$ changes discussed here appear to explain the observed granule-level inter-collection $r_{\mathrm{e}, 3.7}$ differences (Fig. 6c), which for the case study granule are strongly positive (C6 larger) or negative (C6 smaller) and are seemingly dependent on view angle. Nevertheless, it is difficult to determine how the granule-level $r_{\mathrm{e}, 3.7}$ differences 

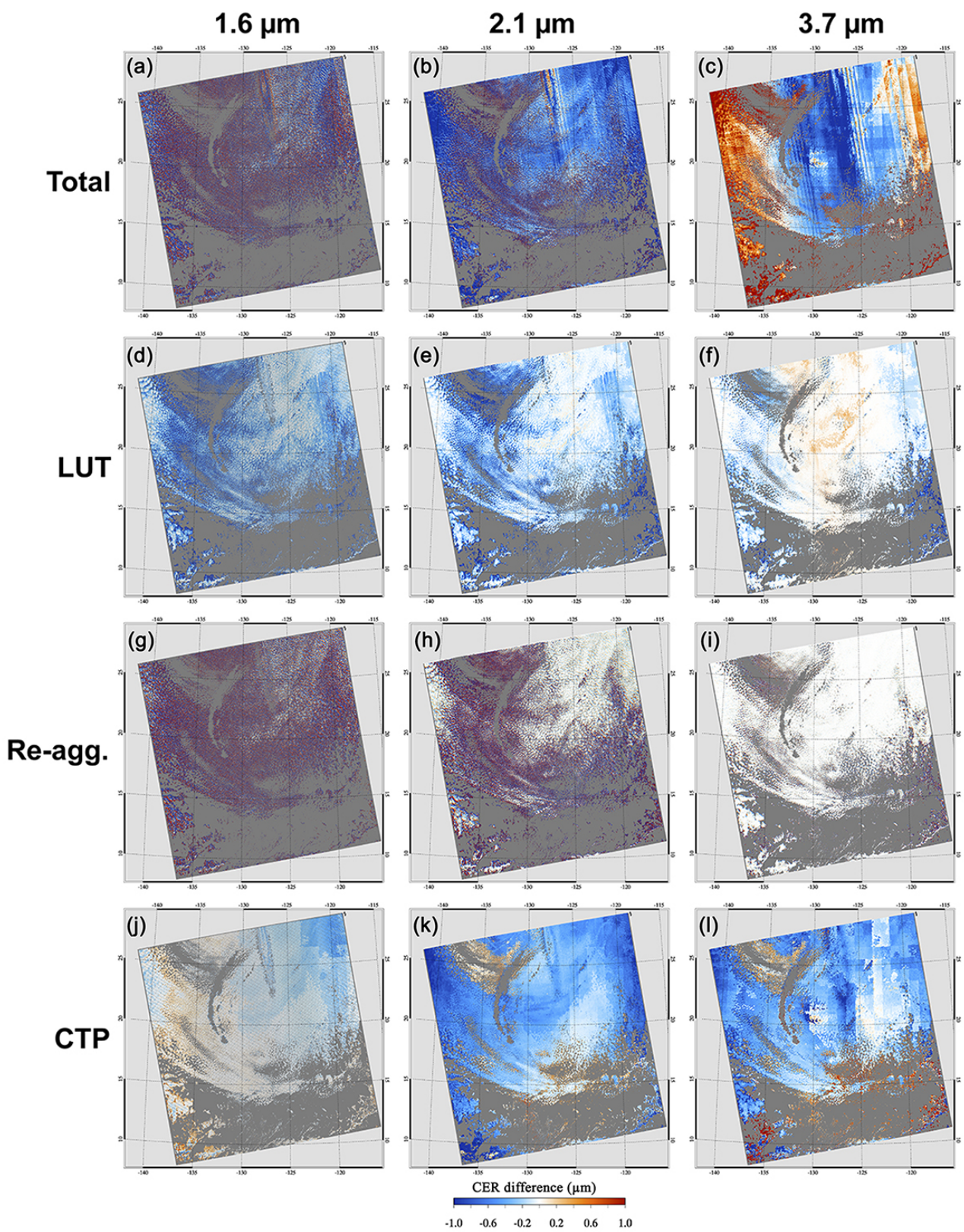

Figure 6. C6-C5.1 $r_{\mathrm{e}}$ retrieval differences for the granule shown in Fig. 5 for $r_{e 1.6}, r_{\mathrm{e}, 2.1}$, and $r_{\mathrm{e}, 3.7}$ effective radii (a-c) in total and contributions from $(\mathbf{d}-\mathbf{f})$ lookup table differences, $(\mathbf{g}-\mathbf{i})$ pixel reaggregation, and $(\mathbf{j}-\mathbf{l})$ cloud-top pressure.

translate to the global aggregated differences in Fig. 2. In addition, given the extensive $\mathrm{C} 6$ changes and the known shortcomings of the C5.1 $r_{\mathrm{e}, 3.7}$ retrievals, it is of limited benefit to further assess their inter-collection differences.

A final consideration regarding the inter-collection CDNC differences shown in Fig. 3 is the fact that CDNC estimates from the retrieved cloud optical properties also depend on the retrieved cloud-top temperature through the $c_{w}$ parameter. As discussed above and in Sect. 2, a number of algorithm improvements were implemented in the C6 MYD06 cloud- top property product, including cloud-top retrievals at $1 \mathrm{~km}$ resolution in addition to the $5 \mathrm{~km}$ cloud-top retrievals that have heritage to C5.1 and earlier collections (Baum et al., 2012). For the C6 CDNC estimates in this study, the $1 \mathrm{~km}$ CTT is used. To assess the impact of differences in CTT on CDNC, the CTT values from C5.1 at $5 \mathrm{~km}$ and C6 at $1 \mathrm{~km}$ were aggregated to $1^{\circ} \times 1^{\circ}$ for the common pixel population, shown in Fig. 4b. The differences in CTT reveal a relatively lower temperature $(3 \mathrm{~K})$ from $\mathrm{C} 6$ in subsidence regions at low latitudes, neutral to slightly positive differences at higher 


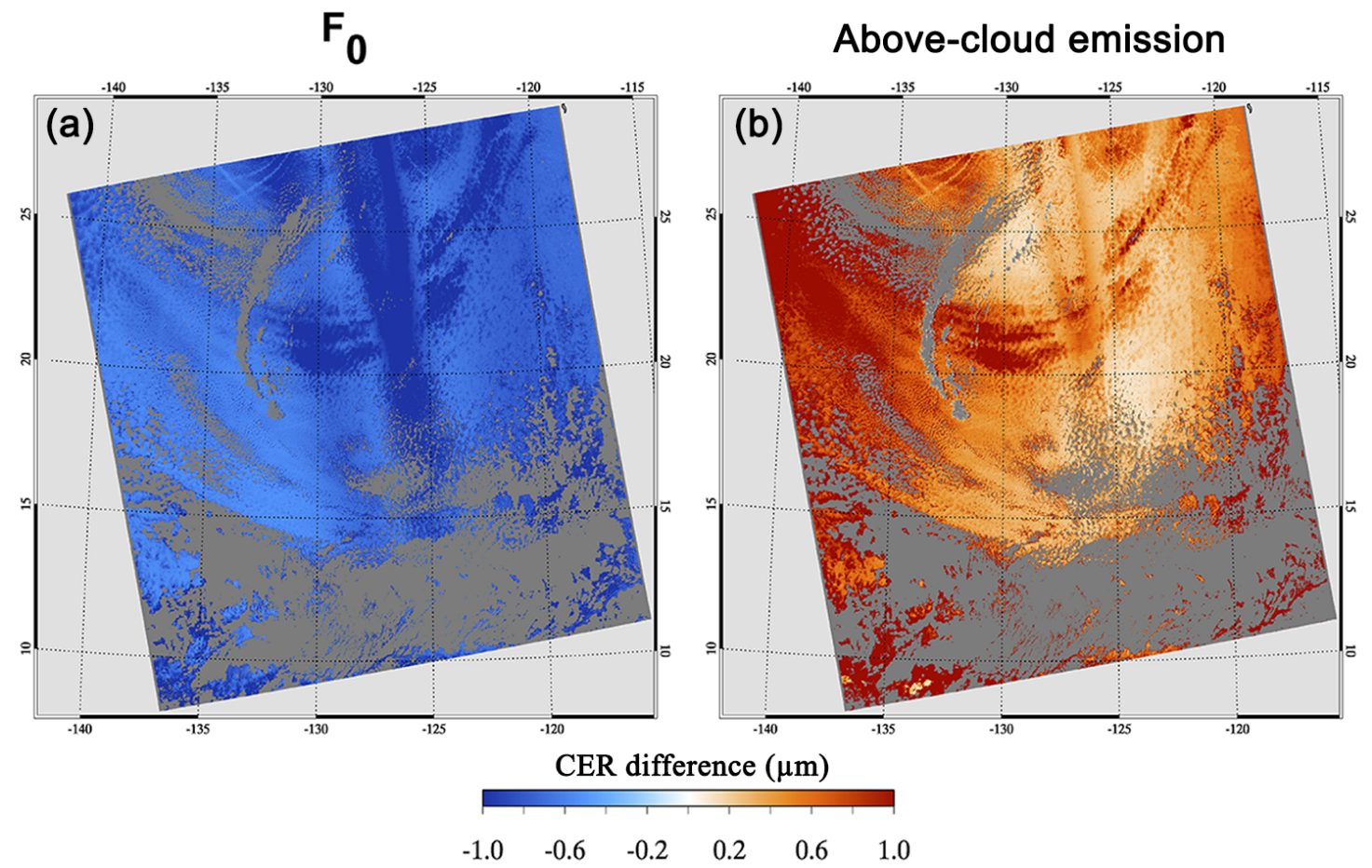

Figure 7. C6-C5.1 $\mathrm{r}_{e, 3.7}$ retrieval differences due to (a) the change of the assumed solar irradiance $\left(F_{0}\right)$ at $3.7 \mu \mathrm{m}$ and (b) correctly accounting for above-cloud atmospheric emission previously ignored in C5.1.

latitudes, and largely positive differences in the intertropical convergence zone. Although the CTP increases in subsidence regions between collections, CTP placement is independent of CTT changes between collections, which creates a seemingly contradictory situation when viewed together. To determine how the disagreement in CTT translates to CDNC apart from the cloud-top retrieval impacts to $r_{\mathrm{e}}$, the $c_{w}$ was also aggregated to $1^{\circ} \times 1^{\circ}$. The differences in $c_{w, 6}$ and $c_{w, 5.1}$ translate to a $0.5 \%$ relative decrease in globally averaged $N$ for C6, provided all other parameters are held constant. The largest observed difference is in the subtropical subsidence regions, where the decrease is near $4 \%$. Therefore, $c_{w}$ has only a marginal impact on $N$ for any of the three absorption channels, a result that provides further evidence in favor of attributing inter-collection $N$ differences largely to changes in the effective radius retrievals.

\subsection{Regional common pixel comparison}

Four maritime regions were selected for additional examination primarily for their proximity to sources of anthropogenic aerosols and generally high number of liquid cloud observations within their domains: southern Africa (SAF), South America (SAM), North America (NAM), and Southeast Asia (SEA). The boundaries of these regions are shown as white outlines in Fig. 1.

The annual CDNC cycles from C5.1 and C6 are given in Fig. 8a for the southern Africa region. Similar to the global results, the 1.6 and $2.1 \mu \mathrm{m}$ CDNC from $\mathrm{C} 6$ are systematically higher $\left(>10 \mathrm{~cm}^{-3}\right)$, while the C6 $3.7 \mu \mathrm{m}$ values vary from being lower $\left(<10 \mathrm{~cm}^{-3}\right)$ to near agreement with $\mathrm{C} 5.1$. During the southern African dry biomass burning season between June and October (Roberts et al., 2009), the $1.6 \mu \mathrm{m}$ C6 CDNC presents the greatest differences between collections, exceeding $30 \mathrm{~cm}^{-3}$ with a maximum CDNC of over $180 \mathrm{~cm}^{-3}$. Interestingly, there is no discernable difference at $3.7 \mu \mathrm{m}$ for either collection over the biomass burning season; however, it is quite muted relative to $N_{1.6}$; peak values during the season are roughly in agreement with Austral summer values between 90 and $100 \mathrm{~cm}^{-3}$. For the region, absorbing aerosols from biomass burning often overlie the cloud deck, decreasing the reflected radiation observed by MODIS. With increasing aerosol optical depth, this can result in decreased retrieved cloud optical thickness and a general decrease in retrieved effective radius (Haywood et al., 2004). The sensitivity to overlying aerosols on the retrieved quantities depends on the degree of orthogonality of the retrieval solution space. Since CDNC estimates are significantly more sensitive to $r_{\mathrm{e}}$ changes than optical thickness, the decrease in $r_{\mathrm{e}}$ may result in an overestimation of CDNC if overlying absorbing aerosols are present. Results from the SAM region in Fig. 8b show a stratification and general response between collections, which is similar to SAF. For this region, a generally consistent aerosol emission rate gives rise to little variability (Huneeus et al., 2006) in CDNC, with annual cycle ampli- 


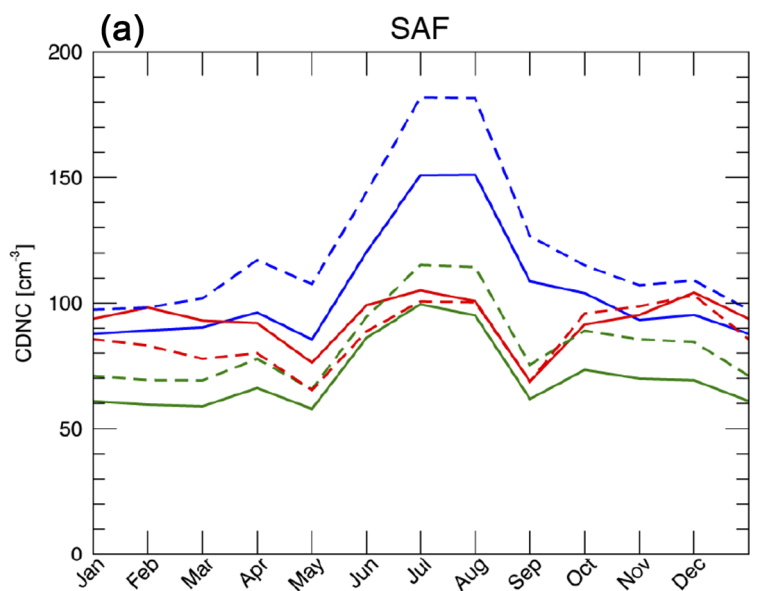

(c)

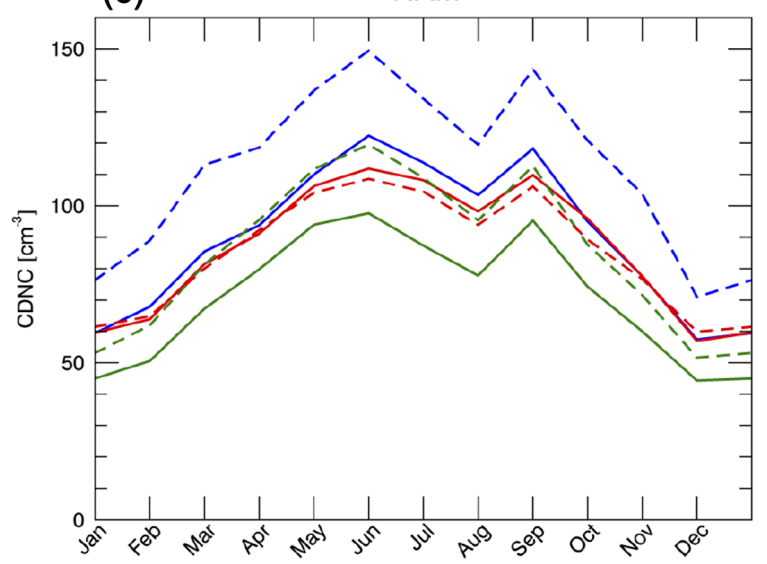

(b)

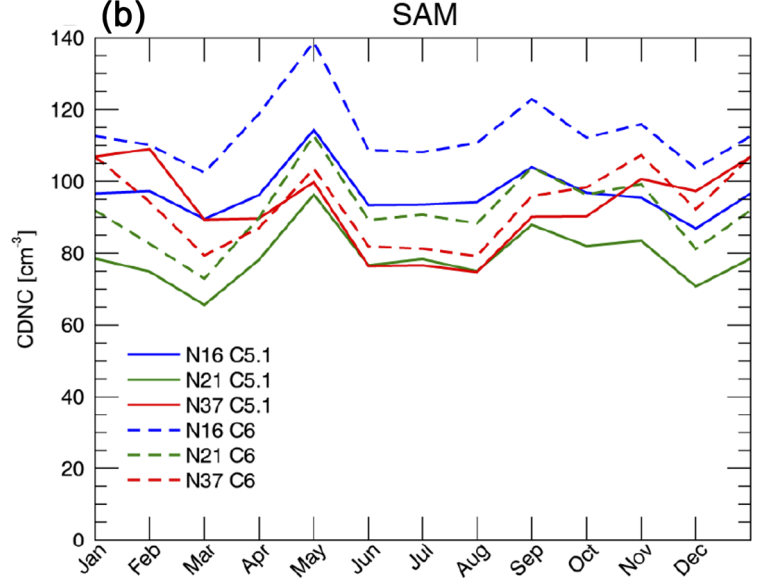

(d)

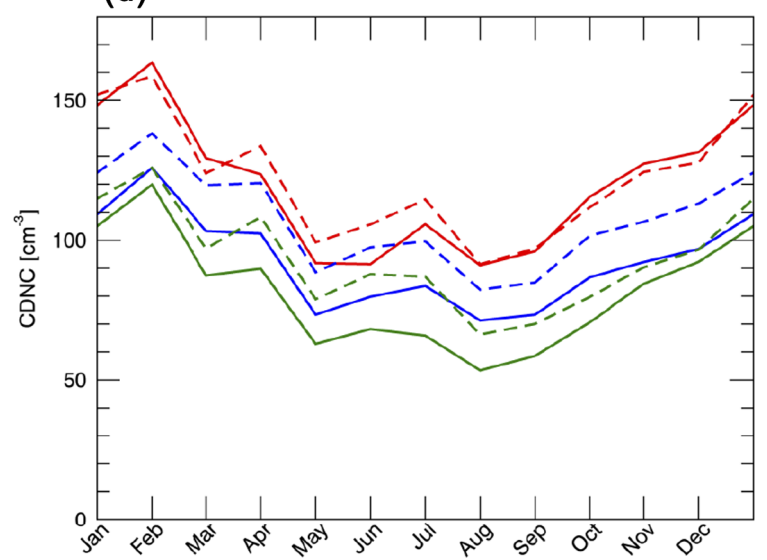

Figure 8. Annual CDNC cycle plots for the (a) southern African, (b) South American, (c) North American, and (d) Southeast Asian regions.

tudes limited to a range of approximately $20 \mathrm{~cm}^{-3}$ across all channels for both collections. For NAM, the common pixel comparison also yields similar results to the previous regions as shown in Fig. 8c. For this region, both the 1.6 and $2.1 \mu \mathrm{m}$ channels also exhibit a $20-30 \mathrm{~cm}^{-3}$ difference for Collection 6 retrievals while $3.7 \mu \mathrm{m}$ is in near agreement with Collection 5.1. All three channels have a uniform response to increases in CDNC coincident with a relatively early wildfire season that occurred during the spring and summer of 2008 in California (Brioude et al., 2009).

In contrast to the other regions in the study, the SEA domain yields a different stratification of CDNC shown in Fig. 8d, where $N_{3.7}>N_{1.6}>N_{2.1}$ for both collections with general agreement between $N_{3.7}$ retrievals. Disagreements between collections are less than $15 \mathrm{~cm}^{-3}$ for each channel. The different stratification may be a result of differing cloud dynamics in this region due to a weaker inversion strength, resulting in greater entrainment compared to the other regions which lie in subsidence zones. There is a strong seasonal response to aerosols visible in each channel coincident with the advection of aerosols by the Asian winter monsoon (Bennartz et al., 2011).
The adiabatic model assumes the retrieved effective radius is the near-cloud-top value. For an ideal adiabatically stratified cloud $r_{\mathrm{e}, 3.7}>r_{\mathrm{e}, 2.1}>r_{\mathrm{e}, 1.6}$, implying that $N_{1.6}>N_{2.1}>N_{3.7}$, as each effective radius retrieval has a varying vertical penetration depth. None of the focus regions in this study exhibit this behavior. In addition to entrainment processes, retrieved droplet effective radius and therefore estimated CDNC can be influenced by drizzle processes (Suzuki et al., 2010) or 3-D radiative transfer effects and cloud field inhomogeneity at the sub-pixel level that violate the plane-parallel cloud assumption used in the optical properties retrieval (Zhang and Platnick, 2011). Since values in this study are aggregated to $1 \times 1^{\circ}$ and averaged monthly with no screening criteria with respect to vertical stratification, it is likely these processes are contributing to the nonadiabatic stratification observed.

\section{Conclusions}

It has previously been shown, under the condition of adiabatic clouds, that estimates of the CDNC of warm marine 
liquid-phase clouds can be derived from passive satellite remote sensing observations. To this end, observations from MODIS on the Terra and Aqua satellites have seen wide use. The operational MODIS cloud product (MYD06 for Aqua) provides the cloud property retrievals necessary for computing CDNC estimates, namely cloud-top temperature, cloud optical thickness, and effective droplet radius $\left(r_{\mathrm{e}}\right)$. Collection 6 , the most recent release of MYD06, includes numerous updates relative to its predecessor, Collection 5.1, that can propagate through to estimates of CDNC. Using 1 year (2008) of global MODIS-Aqua observations, inter-collection differences are investigated for CDNC derived from three independent spectral $r_{\mathrm{e}}$ retrievals, namely from the 1.6, 2.1, and $3.7 \mu \mathrm{m}$ channels. For the pixel population having successful $r_{\mathrm{e}}$ retrievals from all three spectral channels in both collections, C6 $r_{\mathrm{e}, 1.6}$ and $r_{\mathrm{e}, 2.1}$ retrievals are smaller than those of $\mathrm{C} 5.1$, with the greatest differences generally found for $r_{\mathrm{e}, 1.6}$. These inter-collection $r_{\mathrm{e}}$ differences result in relatively larger estimates of C6 CDNC for both channels. Nevertheless, CDNC from these two spectral channels offer similar annual cycles for both C5.1 and C6, regardless of the geographic region. $N_{3.7}$ differences in stratocumulus regions are generally smaller and, unlike $N_{1.6}$ and $N_{2.1}$, the signs of the differences are rarely uniform throughout the annual cycle. Moreover, the global inter-collection differences in $r_{\mathrm{e}, 3.7}$ and $N_{3.7}$ exhibit quite different behavior than those derived from the 1.6 and $2.1 \mu \mathrm{m}$ channels. These differences are inherently attributable to the more wholesale $\mathrm{C} 6$ changes that addressed known shortcomings in the C5.1 $r_{\mathrm{e}, 3.7}$ retrieval. But because the individual effects of the $\mathrm{C} 6$ changes can be quite large, are often of opposite sign, and have angular and potentially other unknown dependencies, it remains unclear how granule-level $r_{\mathrm{e}, 3.7}$ differences translate to the global aggregated differences shown here. Additional research is necessary in order to quantify the contribution of these dependencies to the observed inter-collection differences of $r_{\mathrm{e}, 3.7}$ and $N_{3.7}$. Furthermore, it is recommended that quantitative use of the C5.1 $r_{\mathrm{e}, 3.7}$ retrieval be avoided given its known shortcomings.

Among the updates for $\mathrm{C} 6$ is the independent reporting of $r_{\mathrm{e}}$ for each wavelength, rather than as differences with respect to $r_{\mathrm{e}, 2.1}$, as well as the inclusion of retrievals of the so-called partly cloudy pixels previously discarded in C5.1. These changes offer additional options in the analysis of CDNC from MODIS. Several permutations in data screening scenarios beyond those used in this study are now available, which were not possible in C5.1, and will likely be explored in future studies. Caution will be warranted when interpreting the results of these and other future studies of $r_{\mathrm{e}}$ and CDNC intercomparisons which may be subject to different screening criteria available in C6 which allows for the inclusion of more potentially problematic retrievals. The differences observed here are only for overcast scenes for pixels in which all three effective radius retrievals are valid for liquid phase clouds. Different screening criteria may exacerbate the effects of aggregated retrieval artifacts, which have not been considered in this study.

Data availability. The aggregated observations from MODIS collections 5.1 and 6 used in this study are available at https://doi.org/10.15695/vudata.ees.2 (Rausch and Bennartz, 2017).

Competing interests. The authors declare that they have no conflict of interest.

Acknowledgements. The authors thank two anonymous reviewers whose input greatly improved this paper.

Edited by: B. Mayer

Reviewed by: two anonymous referees

\section{References}

Ahmad, I., Mielonen, T., Grosvenor, D. P., Portin, H. J., Arola, A., Mikkonen, S., Kuhn, T., Leskinen, A., Joutsensaari, J., Komppula, M., Lehtinen, K. E. J., Laaksonen, A., and Romakkaniemi, S.: Long-term measurements of cloud droplet concentrations and aerosol-cloud interactions in continental boundary layer clouds, Tellus B, 65, 20138, https://doi.org/10.3402/tellusb.v65i0.20138, 2013.

Albrecht, B. A.: Aerosols, Cloud Microphysics, and Fractional Cloudiness, Science, 245, 1227-1230, 1989.

Baum, B. A., Menzel, W. P., Frey, R. A., Tobin, D. C., Holz, R. E., Ackerman, S. A., Heidinger, A. K., and Yang, P.: MODIS CloudTop Property Refinements for Collection 6, J. Appl. Meteorol. Clim., 51, 1145-1163, 2012.

Bennartz, R.: Global assessment of marine boundary layer cloud droplet number concentration from satellite, J. Geophys. Res.Atmos., 112, D02201, https://doi.org/10.1029/2006jd007547, 2007.

Bennartz, R., Fan, J. W., Rausch, J., Leung, L. R., and Heidinger, A. K.: Pollution from China increases cloud droplet number, suppresses rain over the East China Sea, Geophys. Res. Lett., 38, L09704, https://doi.org/10.1029/2011GL047235, 2011.

Brenguier, J. L., Pawlowska, H., Schuller, L., Preusker, R., Fischer, J., and Fouquart, Y.: Radiative properties of boundary layer clouds: Droplet effective radius versus number concentration, J. Atmos. Sci., 57, 803-821, 2000.

Brenguier, J.-L., Burnet, F., and Geoffroy, O.: Cloud optical thickness and liquid water path - does the $k$ coefficient vary with droplet concentration?, Atmos. Chem. Phys., 11, 9771-9786, https://doi.org/10.5194/acp-11-9771-2011, 2011.

Brioude, J., Cooper, O. R., Feingold, G., Trainer, M., Freitas, S. R., Kowal, D., Ayers, J. K., Prins, E., Minnis, P., McKeen, S. A., Frost, G. J., and Hsie, E.-Y.: Effect of biomass burning on marine stratocumulus clouds off the California coast, Atmos. Chem. Phys., 9, 8841-8856, https://doi.org/10.5194/acp-9-8841-2009, 2009.

Cho, H. M., Zhang, Z. B., Meyer, K., Lebsock, M., Platnick, S., Ackerman, A. S., Di Girolamo, L., C.-Labonnote, L., Cor- 
net, C., Riedi, J., and Holz, R. E.: Frequency and causes of failed MODIS cloud property retrievals for liquid phase clouds over global oceans, J. Geophys. Res.-Atmos., 120, 4132-4154, https://doi.org/10.1002/2015jd023161, 2015.

Cox, C. and Munk, W.: Statistics of the sea surface derived from Sun glitter, J. Marine Res., 13, 198-227, 1954a.

Cox, C. and Munk, W.: Measurement of the Roughness of the Sea Surface from Photographs of the Sun's Glitter, J. Opt. Soc. Am., 44, 838-850, https://doi.org/10.1364/JOSA.44.000838, 1954b.

Duynkerke, P. G., de Roode, S. R., van Zanten, M. C., Calvo, J., Cuxart, J., Cheinet, S., Chlond, A., Grenier, H., Jonker, P. J., Kohler, M., Lenderink, G., Lewellen, D., Lappen, C. L., Lock, A. P., Moeng, C. H., Muller, F., Olmeda, D., Piriou, J. M., Sanchez, E., and Sednev, I.: Observations and numerical simulations of the diurnal cycle of the EUROCS stratocumulus case, Q. J. Roy. Meteorol. Soc., 130, 3269-3296, https://doi.org/10.1256/Qj.03.139, 2004.

Haywood, J. M., Osborne, S. R., and Abel, S. J.: The effect of overlying absorbing aerosol layers on remote sensing retrievals of cloud effective radius and cloud optical depth, Q. J. Roy. Meteorol. Soc., 130, 779-800, https://doi.org/10.1256/qj.03.100, 2004.

Ho, S. P., Peng, L., Anthes, R. A., Kuo, Y. H., and Lin, H. C.: Marine Boundary Layer Heights and Their Longitudinal, Diurnal, and Interseasonal Variability in the Southeastern Pacific Using COSMIC, CALIOP, and Radiosonde Data, J. Climate, 28, 28562872, https://doi.org/10.1175/Jcli-D-14-00238.1, 2015.

Huneeus, N., Gallardo, L., and Rutllant, J. A.: Offshore transport episodes of anthropogenic sulfur in northern Chile: Potential impact on the stratocumulus cloud deck, Geophys. Res. Lett., 33, L19819, https://doi.org/10.1029/2006g1026921, 2006.

Lohmann, U. and Feichter, J.: Global indirect aerosol effects: a review, Atmos. Chem. Phys., 5, 715-737, https://doi.org/10.5194/acp-5-715-2005, 2005.

Marchant, B., Platnick, S., Meyer, K., Arnold, G. T., and Riedi, J.: MODIS Collection 6 shortwave-derived cloud phase classification algorithm and comparisons with CALIOP, Atmos. Meas. Tech., 9, 1587-1599, https://doi.org/10.5194/amt-9-1587-2016, 2016.

Martin, G. M., Johnson, D. W., and Spice, A.: The Measurement and Parameterization of Effective Radius of Droplets in Warm Stratocumulus Clouds, J. Atmos. Sci., 51, 1823-1842, 1994.

Nakajima, T. and King, M. D.: Determination of the OpticalThickness and Effective Particle Radius of Clouds from Reflected Solar-Radiation Measurements, 1. Theory, J. Atmos. Sci., 47, 1878-1893, 1990.

Painemal, D. and Zuidema, P.: Assessment of MODIS cloud effective radius and optical thickness retrievals over the Southeast Pacific with VOCALS-REx in situ measurements, J. Geophys. Res.-Atmos., 116, D24206, https://doi.org/10.1029/2011jd016155, 2011.
Pawlowska, H. and Brenguier, J. L.: An observational study of drizzle formation in stratocumulus clouds for general circulation model (GCM) parameterizations, J. Geophys. Res.-Atmos., 108, 8630, https://doi.org/10.1029/2002jd002679, 2003.

Platnick, S.: Vertical photon transport in cloud remote sensing problems, J. Geophys. Res.-Atmos., 105, 22919-22935, 2000.

Platnick, S., King, M. D., Meyer, K. G., Wind, G., Amarasinghe, N., Marchant, B., Arnold, G. T., Zhang, Z., Hubanks, P. A., Ridgway, W., and Riedi, J.: MODIS Cloud Optical Properties: User Guide for the Collection 6 Level-2 MOD06/MYD06 Product and Associated Level-3 Datasets, 2015.

Platnick, S., Meyer, K. G., D., K. M., Wind, G., Amarasinghe, N., Marchant, B., Arnold, G. T., Zhang, Z., Hubanks, P. A., Holz, R. E., Yang, P., Ridgway, W. L., and Riedi, J.: The MODIS Cloud Optical and Microphysical Products: Collection 6 Updates and Examples From Terra and Aqua, IEEE T. Geosci. Remote, 55, 502-525, https://doi.org/10.1109/TGRS.2016.2610522, 2017.

Rausch, J. and Bennartz, R.: Cloud Droplet Number Concentration from MODIS Collections 5.1 and 6 for 2008, https://doi.org/10.15695/vudata.ees.2, 2017.

Roberts, G., Wooster, M. J., and Lagoudakis, E.: Annual and diurnal african biomass burning temporal dynamics, Biogeosciences, 6 , 849-866, https://doi.org/10.5194/bg-6-849-2009, 2009.

Suzuki, K., Nakajima, T. Y., and Stephens, G. L.: Particle Growth and Drop Collection Efficiency of Warm Clouds as Inferred from Joint CloudSat and MODIS Observations, J. Atmos. Sci., 67, 3019-3032, https://doi.org/10.1175/2010jas3463.1, 2010.

Twomey, S.: Pollution and Planetary Albedo, Atmos. Environ., 8, 1251-1256, 1974.

von Engeln, A. and Teixeira, J.: A Planetary Boundary Layer Height Climatology Derived from ECMWF Reanalysis Data, J. Climate, 26, 6575-6590, https://doi.org/10.1175/Jcli-D-1200385.1, 2013.

Zeng, S., Riedi, J., Trepte, C. R., Winker, D. M., and Hu, Y.-X.: Study of global cloud droplet number concentration with A-Train satellites, Atmos. Chem. Phys., 14, 7125-7134, https://doi.org/10.5194/acp-14-7125-2014, 2014.

Zhang, Z. B. and Platnick, S.: An assessment of differences between cloud effective particle radius retrievals for marine water clouds from three MODIS spectral bands, J. Geophys. Res.-Atmos., 116, D20215, https://doi.org/10.1029/2011JD016216, 2011. 